\title{
Does Service Leadership Education Contribute to Student Well-Being? A Quasi-Experimental Study Based on Hong Kong University Students
}

\author{
Li Lin ${ }^{1}$ • Daniel T. L. Shek ${ }^{1}$
}

Received: 29 January 2018 / Accepted: 29 May 2018/Published online: 10 June 2018

(C) The Author(s) 2018

\begin{abstract}
Leadership programs have become increasingly prevalent in tertiary institutions, but rigorous evaluation research on their effectiveness on student development, particularly student well-being is inadequate. This study examined the effectiveness of a credit-bearing leadership course entitled "Service Leadership" in promoting leadership capacities and well-being of university students using a pretest-posttest quasi-experimental design. Based on a sample of Hong Kong university students (experimental group: $n=$ 75; control group, $n=105$ ), we found that students in the experimental group (i.e., those taking the course) showed a greater improvement in service leadership knowledge, service leadership attitudes, and life satisfaction than those in the control group (i.e., those not taking the course) after taking the course. Besides, changes in life satisfaction and positive youth development were positively related to the change in service leadership attitudes but not service leadership knowledge. The implications of the findings on leadership education and holistic development of university students are discussed.
\end{abstract}

Keywords Service leadership model $\cdot$ Service leadership knowledge $\cdot$ Service leadership attitudes · Life satisfaction · Positive youth development

\section{Introduction}

With the belief that the future societal wellness and quality of life are tied to the development of effective leaders (Ewing et al. 2009), nurturing students' leadership capacities has become an important mission of higher education (Cress et al. 2001). In

The authorship is equally shared by the first author and second author.

Daniel T. L. Shek

daniel.shek@polyu.edu.hk

1 Department of Applied Social Sciences, The Hong Kong Polytechnic University, Hunghom, Hong Kong, People's Republic of China 
fact, many leadership education and training programs have been offered in colleges and universities in both curricular and co-curricular forms (e.g., Brungardt et al. 2006; Riggio et al. 2003; Sessa et al. 2009; Shek et al. 2017e).

Despite the proliferation of leadership programs, several gaps in the literature should be noted. First, most studies that examined the impacts of leadership programs on student development did not clearly show the relationship between the leadership programs and student development (Shek and $\mathrm{Ng} \mathrm{2017),} \mathrm{as} \mathrm{they}$ often relied on one-group pretest-posttest design (e.g., Binard and Brungardt 1997) or correlational study linking leadership program experience to student developmental outcomes (e.g., Dugan and Komives 2010). Second, when investigating the impacts of leadership programs, researchers or practitioners have seldom taken student well-being into account (see Cress et al. 2001; Dugan and Komives 2007). This aspect is important because leadership program is generally implemented to promote personal growth, which possibly contributes to wellbeing (Ryan and Deci 2001). Finally, it is not clear about how leadership programs are related to different aspects of student well-being.

This study was thus conducted to fill these gaps based on a leadership course entitled "Service Leadership" offered to undergraduate students in Hong Kong. First, we examined the effects of the course on leadership capacities and personal well-being of students by adopting a quasi-experimental design. Additionally, we explored the associations between the change in leadership capacities and the change in personal well-being. Findings of this study would shed light on the relationship of leadership program and student well-being, and bring new insights to the leadership development theory and leadership program implementation.

\section{Leadership Programs in Higher Education}

In the late twentieth century, the developed industrial countries and areas experienced a remarkable transformation of economic structure from manufacturing economy into service economy (Astin and Astin 1996; Chung and Bell 2012; Rost 1991). Leaders in the new service era are expected to be willing and capable to provide professional service, collaborate with others, manage social relationship, demonstrate moral values, empower their followers rather than simply boosting their authority, controlling their followers and maximizing productivity (Lusch et al. 2007; Rost 1991). Against this background, theories and models about leadership development of college students tended to regard leadership as a relational and ethical process, in which people of different parties collaborate to achieve an aspiration that contributes to common good, such as the social change model of leadership development (Astin and Astin 1996), relational leadership model (Komives et al. 2005), leadership challenge model (Kouzes and Posner 2002), and service leadership model (Chung and Bell 2012; Shek et al. 2018). For example, social change model proposed to promote students' leadership development based on social responsibility, which consists of seven core values across individual domain (i.e., consciousness of self, congruence, and commitment), group domain (i.e., collaboration, common purpose, and controversy with civility), and societal domain (i.e., citizenship; Astin and Astin 1996). The advocates (e.g., Dugan 
and Komives 2007) believed that these leadership capacities enable students to make a social change for the common good.

Another example is the service leadership model proposed by Po Chung, the cofounder of DHL International (Chung and Bell 2012). Service leadership was defined as "satisfying needs by consistently providing quality personal service to everyone one comes into contact with, including one's self, others, groups, communities, systems, and environments" (Chung 2011). In contrast with the notion that regards leadership as an instrument for boosting fame and profit, service leadership regards the willingness and capacity to provide service as the essential quality of leaders. The major principle of practicing service leadership is to demonstrate competencies, moral character, and caring disposition, because these qualities would determine the service leadership effectiveness (Shek et al. 2018). Service leadership places greater importance on moral character and caring disposition, as they are believed to largely affect the trustworthiness of the leaders, which is critical in service economies (Chung and Bell 2015). Furthermore, service leadership emphasizes each person's potential and capacities in developing and practicing leadership regardless of their positions, acknowledges that "everyone is (and can be) a leader", and encourages continuous commitment to making self-improvement (Shek et al. 2018).

According to the contemporary leadership development models, leadership programs have shifted their focus on building up management skills to that on cultivating collaboration qualities, caring disposition, moral values, and other capacities that facilitate the attainment of common good (Rost and Barker 2000). Leadership programs are usually intentionally designed and offered to students to provide them with opportunities to learn knowledge, skills, values and beliefs related to leadership (Haber 2006). They include leadership training, leadership education and leadership development, which are subtly different (Dugan et al. 2011). While leadership training focuses on skill building in specific areas such as conflict resolution and effective communication, leadership education extends the learning beyond the acquisition of functional skills to enhance students' knowledge and capacities across a variety of contexts, and leadership development emphasizes personal growth in leadership learning such as deepening self-understanding.

Previous studies have shown that leadership program experience in the college period is related to students' greater leadership capacity. For example, a national survey in the United State found that students who had ever participated in short-, moderate-, and long-term formal leadership programs reported greater leadership efficacy and social responsible leadership capacity than those non-participants (Dugan and Komives 2007). Another study based on ten tertiary institutions in the United States found that students with experience in leadership programs demonstrated higher levels of leadership understanding and commitment, leadership skills, personal and societal values, civic responsibility, as well as multicultural awareness and community orientation than those without such experience (Cress et al. 2001). Additionally, a few program evaluation studies also reported the effectiveness of leadership education programs. For example, based on the social change model, Rosch and Caza (2012) found that students showed greater leadership capacities in the commitment to serving the collectives, working with a common purpose, handling controversy with civility, and citizenship after joining the voluntary short-term leadership programs. 


\section{Research Gaps}

Inspiringly, this body of literature indicates that leadership programs help with the leadership development of college students. However, few studies are able to inform the causal relationship between leadership program and students' developmental outcomes. Previous studies often used the correlational design (e.g., Dugan and Komives 2010), the pretest-posttest design without a control group (e.g., Rosch and Caza 2012) or the posttest-only design (e.g., Black and Earnest 2009), while these research designs are low in internal validity. In other words, it is still not clear whether participation in leadership programs leads to students' improvement in leadership capacities. The ideal solution to this question is to examine the impact of leadership programs by using a true experimental design with random allocation of participants. However, it is difficult to adopt a true experimental design in an evaluation study of leadership program because participants usually choose to join a program based on their interests and schedules. Thus, a more feasible solution is to adopt a quasi-experimental design. Admittedly, compared with a true experimental design, a quasi-experimental design is weaker in demonstrating a causal relationship, but it can provide information to infer causal relationship by including a control group, and it has greater external validity (Royse et al. 2010).

Furthermore, previous studies primarily focused on the effect of leadership programs on diverse leadership capacities, while overlooked the effects on student well-being. Although it is justifiable that student well-being may not be the intended learning outcome of a leadership program, leadership program is possibly contributive to the enhancement of student well-being. Well-being can be conceptualized into hedonistic well-being which refers to the presence of pleasure and absence of pain, and eudaimonic well-being which pertains to personal growth and degree to which the said individual is fully functioning (Ryan and Deci 2001). A leadership program aimed to enhance leadership capacities actually represents an endeavor to enhance personal growth of students. If students have an improvement in leadership capacities, they would probably experience a sense of growth and an increase in positive functioning, which are the essence of eudaimonic well-being. In addition, leadership education may also improve students' hedonistic well-being. The improvement of various leadership capacities may generate self-confidence among students, which brings students good feelings. The improvement of leadership efficacy found in Dugan and Komives's (2007) study has indicated that leadership program may increase students' positive self-evaluation at least in the leadership domain, which may be generalized into overall happiness. However, it is also possible that the leadership learning process is painstaking, which makes the students feel distressed or frustrated. Therefore, it is worth linking leadership program to student well-being. In so doing, we can expand the scopes of leadership development theory and leadership programs.

Given the possible effect of leadership program on student well-being, it is necessary to explore which learning outcome is related to the change of well-being. Good leadership requires a mixture of knowledge, attitudes and skills (Colfax et al. 2010), and thus leadership development usually involves the growth in the knowing, being, and doing (see Komives et al. 2013). However, whether the improvement in their understanding in leadership (i.e., knowledge acquisition), endorsement in beliefs and values favorable for effective leadership (i.e., attitudinal change), or specific skills in 
practicing leadership (i.e., skills improvement) would be related to the increase of student well-being remains to be an interesting theoretical question. Addressing this question would help to explicate the relationship between leadership development and personal well-being, which would bring new insights to the holistic development of college students.

\section{The Current Study}

With reference to the literature gaps mentioned above, we conducted a study with two major objectives. The first objective is to examine the effects of a leadership program on both leadership capacities and well-being of students by using a design with greater internal validity. The second objective is to explore the relationship between leadership capacities and well-being over the learning process. We tried to address these two objectives based on a leadership course entitled "Service Leadership".

\section{The course "Service Leadership"}

According to the aforementioned service leadership model (Chung and Bell 2012; Shek et al. 2018), scholars and practitioners in Hong Kong endeavored to design and implement service leadership programs, in order to nurture students into competent, moral and caring leaders that are required by service economies (for the introduction of different service leadership education initiatives in Hong Kong, see Shek and Chung 2015). The course "Service Leadership" is one of the service leadership education initiatives, which is offered in the authors' institutions for the undergraduates regardless of their majors. This course has thirteen three-hour lectures, with the content including service leadership ideology, intrapersonal and interpersonal competencies, moral character, caring disposition, and other postindustrial leadership models (see Shek et al. 2013). This subject was awarded the Bronze Award in the QS Reimagine Education Awards 2016.

According to Dugan et al.'s (2011) rationale, the course "Service Leadership" is a leadership education and development program instead of leadership training program. Specifically, it underscores the holistic development of students, and thus students are expected to understand the knowledge about service leadership, appreciate service leadership beliefs and practices, reflect on their service leadership capacities, and improve their capacities to practice service leadership upon completion of the course. Besides lecturing, teachers use experiential and reflective learning approaches such as role play, group discussion, group debate, and self-reflection exercises to facilitate students' learning.

Previous studies based on multiple evaluation approaches (i.e., one-group pretest-posttest, post-course subjective outcome evaluation, and qualitative evaluation) have demonstrated the benefits of this course on student development (Shek and Lin 2015). Students who took this course experienced an increase in selfleadership, caring disposition, moral character, service leadership beliefs, life satisfaction, and positive youth development (Shek and Lin 2017). However, without a control group, the previous studies could not exclude the possibility of natural growth in leadership capacities (Dugan and Komives 2010) and wellbeing during the college life (Shek et al. 2017d). 


\section{Research questions and hypotheses}

According to the reasoning above, the first research question we addressed is whether the course "Service Leadership" is effective in enhancing students' leadership capacities and well-being. We attempted to answer this question through a pretest-posttest quasi-experimental design, in which students who took the course "Service Leadership" served as the experimental group whereas students who had never taken any courses related to service leadership served as the control group.

We measured two outcomes related to leadership capacity (i.e., service leadership knowledge and service leadership attitudes). Service leadership knowledge entails the background, concepts, principles, functionality regarding service leadership and its specific components (e.g., intrapersonal and interpersonal competencies, caring disposition, and moral character; Shek et al. 2017c). This body of knowledge (i.e., knowing) serves as a cognitive foundation of service leadership practice (Shek and Lin 2017). Service leadership attitudes refer to a set of attitudes toward desirable leadership qualities and practices upheld by the service leadership model (e.g., readiness to serve others, belief in everyone's potential to be a leader, moral character, caring disposition, continuous commitment to self-improvement; Shek et al. 2017b). The attitudes reflect one's awareness of his/her inner values and beliefs about ideal leadership (i.e., being), which would influence how a person behaves as a leader (Bass and Steidlmeier 1999). Therefore, both service leadership knowledge and attitudes are important parts of leadership capacities that facilitate effective practices of service leadership. Besides, we measured two outcomes representing hedonistic well-being (i.e., life satisfaction) and eudaimonic well-being (i.e., positive youth development), respectively. Life satisfaction refers to the cognitive evaluation on one's life condition, and such a satisfaction is the essential component of hedonistic well-being (i.e., subjective well-being; Ryan and Deci 2001). Positive youth development pertains to optimal functioning in cognitive, social, emotional, moral and behavioral domains, which is regarded as an indicator of eudaimonic well-being (Shek et al. 2017d). We expected that the pretest-posttest change in these outcome variables would vary depending on the experimental vs. control group, insofar, students in the experimental group would experience a greater improvement in leadership capacities (Hypothesis 1) and well-being (Hypothesis 2), compared with those in the control group.

The second question inquires whether the pretest-posttest change in service leadership knowledge and service leadership attitudes would be related to the change in life satisfaction and positive youth development (i.e., correlated change). As there is no study addressing this inquiry before, this part of analysis is exploratory in nature. We did not make any specific hypothesis. However, it was conjectured that changes in the service leadership capacities would be related to changes in well-being attributes.

\section{Data Analysis Plan}

To understand the effectiveness of the course "Service Leadership", we performed four repeated measure ANOVA on four outcomes (i.e., service leadership knowledge, service leadership attitudes, life satisfaction and positive youth development) with pretest-posttest change as a within-subjects variable and the treatment group (i.e., experimental vs. control group) as a between-subjects variable. In addition, to examine 
the associations between the change in service leadership qualities and personal wellbeing, we ran four cross-lagged models in AMOS 22.0 with the overall sample. As shown in Fig. 1, each model contained a pair of a service leadership variable (i.e., knowledge and attitudes) and a well-being variable (i.e., life satisfaction and positive youth development). The correlation of residuals indexed the associations between the change in service leadership capacities and personal well-being (i.e., correlated change). We estimated the correlated change by controlling the concurrent association of variables at the pretest, the temporal stability of each variable, and the cross-lagged effect of one leadership variable on the well-being variable and the reversed crosslagged effect. Such a model allowed us to have a precise and stringent examination on the amount of correspondence in the within-individual changes across two variables while excluding the contamination of other associations of the variables (see Allemand and Martin 2016). It should be noted that these models were saturated models because all variables were associated with each other. Therefore, they had zero degree of freedom and demonstrated a perfect fit to the data. This statistical model was often used to study the correlated change of different personality traits with an ultimate objective to identify a similar acting mechanism underlying the development of multiple traits (see Klimstra et al. 2013). Here, it allowed us to investigate if leadership capacity and well-being grew together during the course.

\section{Methods}

\section{Participants and Procedure}

A pretest-posttest quasi-experimental design was adopted in this study, in which a total of 208 university students participated in the pretest and 190 university students participated in the posttest. 182 students participated in both the pretest and posttest, with 77 students who took the course "Service Leadership" serving as the experimental group and 105 students who had never taken any courses related to service leadership serving as the control group. However, as two students were in the middle age, we removed these two cases from the experimental group in order to reach a conclusion for young people. Therefore, we used a sample of 75 students in the experimental group (Mean age $=20.36, S D=1.60$ ) and 105 students in the control group (Mean age = $19.20, S D=1.23)$. The experimental group was generally older than the control group $\left(t_{(178)}=5.51, p<.001\right)$, but the gender ratios $\left(\chi_{(1)}^{2}=2.42, p>.05\right)$ and grade

Pretest

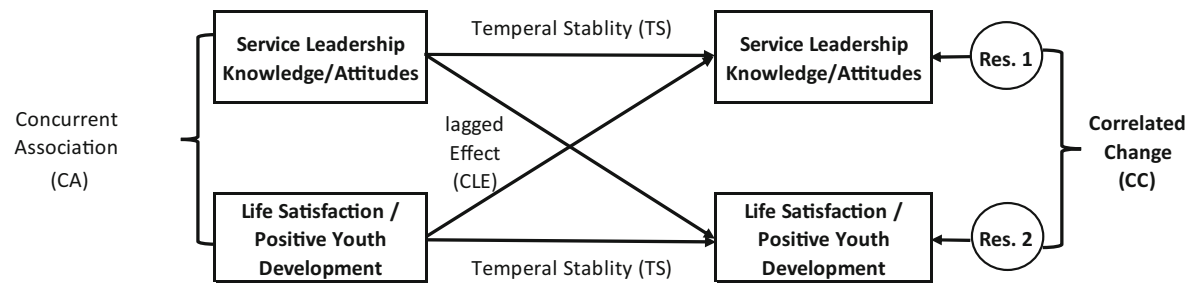

Fig. 1 Illustration of the model of correlated change. Note. Res = residual of the corresponding variable 
distributions $\left(\chi_{(3)}^{2}=3.00, p>.05\right)$ were not different between the two groups (see Table 1).

For the pretest, students completed the first battery of questionnaires in a selfadministrated manner during the first three weeks of the course. For the experimental group, students completed the questionnaires at the first time they attended the lecture. Due to the course add/drop during the first two academic weeks, a few students attended the class from the third week. For the posttest, students completed the questionnaires in a self-administrated manner during the last two academic weeks (i.e., 12th or 13th week). Students' individual informed consent had been obtained before the administration of the pretest.

\section{Instruments}

\section{Well-being}

Life satisfaction was assessed by The Satisfaction with Life Scale (Diener et al. 1985), which has been successfully validated in the Chinese contexts (e.g., Shek 2004). Participants were required to report to what extent they agree or disagree with the five statements (e.g., "The conditions of my life are excellent") on a 6-point Likert scale. Positive youth development was assessed by a 10-item trimmed-version of Chinese Positive Youth Development Scale that has been used in previous studies evaluating the effectiveness of the course "Service Leadership" (Shek et al. 2017a; Shek et al. 2014). Each item measures one positive youth development attribute, including social competence, cognitive competence, emotional competence, behavioral competence, moral competence, self-determination, belief in the future, clear and positive identity, spirituality, and resilience. A mean score was taken to indicate the overall positive youth development level. Both scales demonstrated satisfactory internal consistencies at the pretest and posttest (see Table 2).

\section{Service leadership knowledge}

The 50-item version of The Service Leadership Knowledge Scale (SLK-SF-50) was used to test the "what" about service leadership that the students need to know before they apply service leadership (Shek et al. 2017c). Students were required to answer 50 multiple-choice questions about the major knowledge points, including major principle,

Table 1 Characteristics of participants

\begin{tabular}{|c|c|c|c|c|c|}
\hline \multirow[t]{2}{*}{ Group } & \multicolumn{4}{|c|}{ No. of Participants } & \multirow[b]{2}{*}{ Tota } \\
\hline & Male & & Female & & \\
\hline Experimental & $25(33.3 \%)$ & & $50(66.7 \%)$ & & 75 \\
\hline \multirow[t]{2}{*}{ Control } & $24(22.9 \%)$ & & $81(77.1 \%)$ & & 105 \\
\hline & Grade 1 & Grade 2 & Grade 3 & Grade 4 & \\
\hline Experimental & $52(69.3 \%)$ & $19(25.3 \%)$ & $3(4.0 \%)$ & $1(1.30 \%)$ & 75 \\
\hline Control & $60(57.14 \%)$ & $35(33.33 \%)$ & $8(7.62 \%)$ & $2(1.90 \%)$ & 105 \\
\hline
\end{tabular}




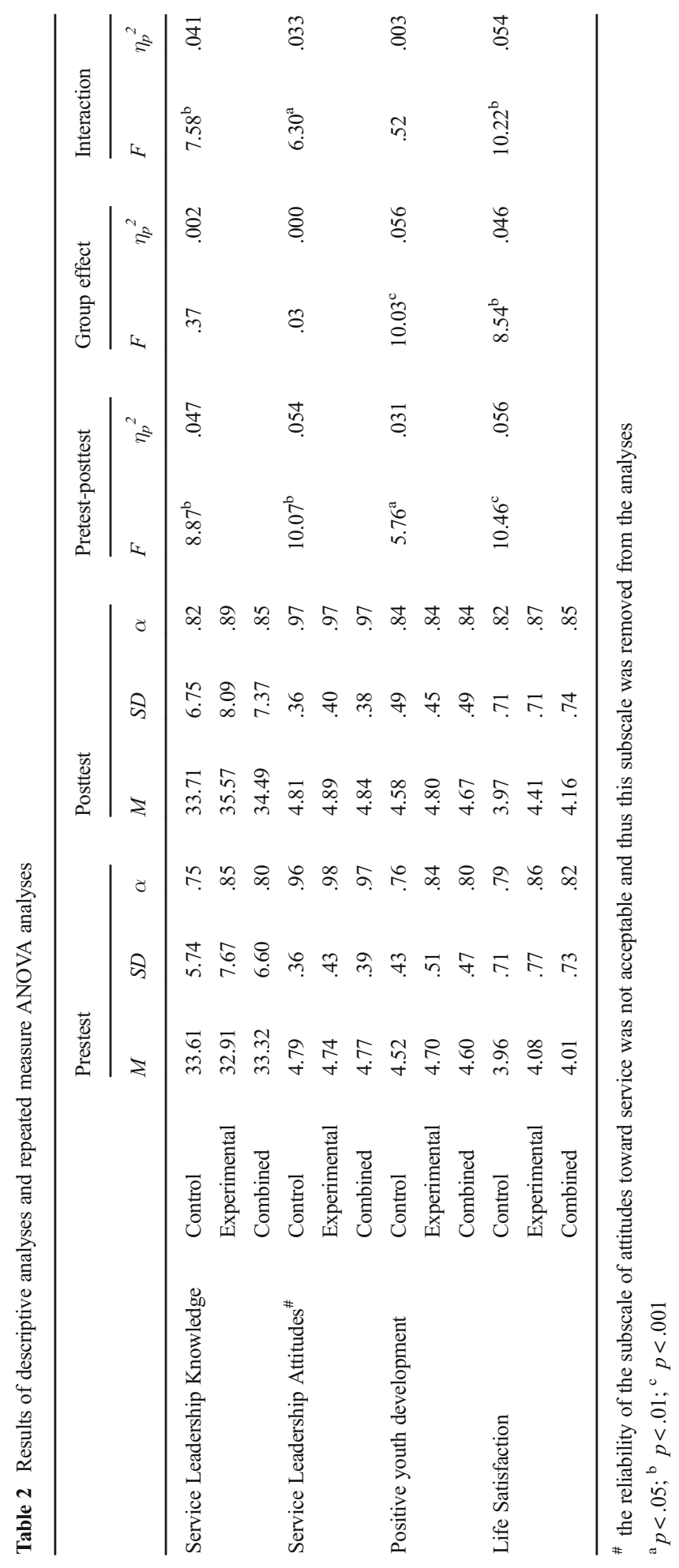


core beliefs, service leadership qualities, and socio-economical background relevant to the service leadership model. The correct answers were coded as 1 and incorrect answers as 0 . A sum score was taken to indicate how much students understand service leadership. A previous study suggests that students who had taken the course "Service Leadership" had better performance on these questions than those who had never taken any courses related to service leadership (Shek and Lin 2017). The internal consistency of SLK-SF-50 was good (see Table 2).

\section{Service leadership attitudes}

The 132-item version of The Service Leadership Attitudes Scale (SLA-LF-132) was developed to measure students' attitudes toward service leadership. Participants indicate their agreement toward 132 statements describing desirable leadership process, qualities, practices that are advocated by the service leadership model on a 6-point Likert scale ( $1=$ strongly disagree; $6=$ strongly agree). A previous study (Shek et al. $2017 \mathrm{~b}$ ) suggests that the content validity of SLA-LF-132 is satisfactory based on three experts' feedbacks. The SLA-LF-132 assesses respondents' attitudes toward ten aspects of description about service leadership. The subscales of service orientation $(\alpha \mathrm{s}=.64 \&$ $.65)$, "everyone can be a leader" ( $\alpha \mathrm{s}=.77 \& .77)$, distributed leadership $(\alpha \mathrm{s}=.76 \&$ $.80)$, employability $(\alpha \mathrm{s}=.78 \& .66)$, personalized service $(\alpha \mathrm{s}=.69 \& .70)$, competencies $(\alpha \mathrm{s}=.96 \& .96)$, moral character $(\alpha \mathrm{s}=.92 \& .90)$, caring disposition $(\alpha \mathrm{s}=.92 \&$ $.92)$, and commitment to continuous improvement $(\alpha \mathrm{s}=.79 \& .78)$ demonstrated acceptable internal consistencies at the pretest and posttest, respectively, but the subscale of attitudes toward service was problematic $(\alpha \mathrm{s}=.13 \&-.15)$. We thus removed this subscale and took a mean score across all the other subscales for the following analyses.

\section{Results}

The first set of analyses were conducted to verify the impact of the course "Service Leadership" on students' service leadership capacities and well-being. At the pretest, four independent $\mathrm{t}$-tests revealed that although the experimental group reported higher levels of positive youth development compared with the control group $\left(t_{(180)}=2.65, p<.01\right)$, there was no group difference (i.e., experimental vs. control group) in the levels of service leadership knowledge, service leadership attitudes and life satisfaction ( $p s>.05)$. These findings indicated that students' backgrounds in the service leadership learning and well-being were generally comparable between the two groups. Next, four repeated measure ANOVA analyses were performed. As shown in Table 2, the pretest-posttest change was significant in all the variables, which indicated there was an upward trend in service leadership knowledge, service leadership attitudes, life satisfaction, and positive youth development from pretest to posttest. Additionally, group differences were detected on the overall levels of life satisfaction and positive youth development, with experimental group (vs. control group) reporting higher levels. More importantly, the interaction effects of group and pretest-posttest change were significant on service leadership knowledge, service leadership attitudes, life satisfaction but not on positive youth development, which 
indicated that students who took the course "Service Leadership" had greater improvement in service leadership knowledge, service leadership attitudes, life satisfaction during the course period, compared with those who had not never taken the course (see Fig. 2). The interaction effects on service leadership knowledge $\left(F_{(1,176)}=4.71, p<.05\right)$, service leadership attitudes $\left(F_{(1,176)}=6.23, p<.05\right)$, life satisfaction $\left(F_{(1,176)}=5.41, p<.05\right)$ remained significant when age and gender were controlled in the analyses. As there was a slight difference in the gender distributions of the experimental and control groups (though the difference was not statistically significant), we also conducted supplemental analyses to verify that such difference did not affect the results. We took 10 random samples of size 75 from the 105 control group participants with 24 males (the maximum number of males was 24) and 51 females, which was comparable to the gender ratio of experimental group. We conducted the repeated measure ANVOA by using these 10 random samples, and the results across different samples remained consistent with the main analyses. Therefore, Hypothesis 1 was supported and Hypothesis 2 was partially supported.

The second set of analyses were conducted to explore the association of the change in service leadership capacities and the change in well-being. As shown in Table 3, service leadership knowledge was only related to positive youth development at the pretest, while service leadership attitudes were positively related to positive youth development and life satisfaction at the pretest and posttest. These preliminary findings suggested that attitudes might be more relevant to well-being. We then used the cross-lagged models to estimate the correlated change of leadership capacities and well-being, and the results were shown in Table 4. For the model of service leadership knowledge and life satisfaction, their correlated change was not significant, adjusting their concurrent association, temporal stabilities, and the cross-lagged effects. Similarly, the correlated change in the model of service leadership knowledge and positive youth development was not significant. Nevertheless, the correlated change in the model of service leadership attitudes and life satisfaction $(\beta=.18$, $p<.05)$ and the model of service leadership knowledge and positive youth development $(\beta=.23, p<.01)$ were both significant. The correlated change between attitudes and life satisfaction $(B=.03, S E=.01, \beta=.18, p<.05)$ and that between attitudes and positive youth development $(B=.03, S E=.01, \beta=.23, p<.05)$ remained significant after age and gender were controlled in the models. These findings suggested that the increase in well-being may be related to the increased endorsement in service leadership attitudes but not the increased acquisition of service leadership knowledge.
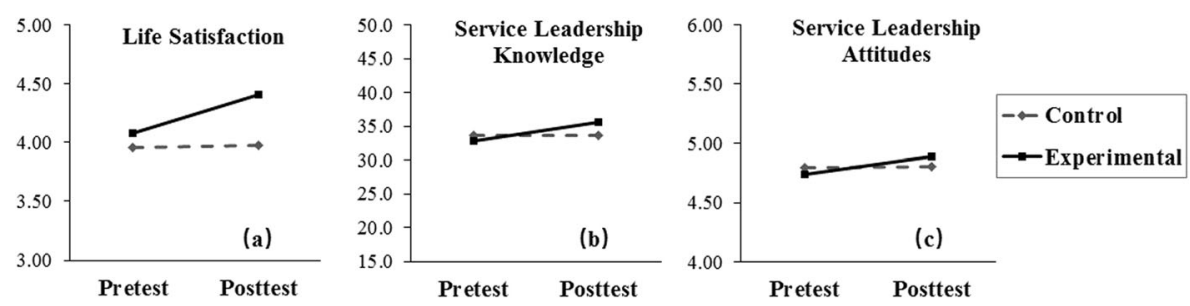

Fig. 2 Interaction effects between pretest-posttest change and group (experimental vs. control group) on life satisfaction (a), service leadership knowledge (b) and, service leadership attitudes (c) 
Table 3 Zero-order correlations of the study variables

\begin{tabular}{|c|c|c|c|c|c|c|c|c|}
\hline & & 1 & 2 & 3 & 4 & 5 & 6 & 7 \\
\hline \multicolumn{9}{|c|}{ Pretest variables } \\
\hline 1 & Service leadership knowledge & & & & & & & \\
\hline 2 & Service leadership attitudes & $.36^{\mathrm{c}}$ & & & & & & \\
\hline 3 & Positive youth development & $.15^{\mathrm{a}}$ & $.43^{\mathrm{c}}$ & & & & & \\
\hline 4 & Life satisfaction & .09 & $.24^{\mathrm{b}}$ & $.51^{\mathrm{c}}$ & & & & \\
\hline \multicolumn{9}{|c|}{ Posttest variables } \\
\hline 5 & Service leadership knowledge & $.60^{\mathrm{c}}$ & $.33^{\mathrm{c}}$ & .09 & $.18^{\mathrm{a}}$ & & & \\
\hline 6 & Service leadership attitudes & $.27^{\mathrm{c}}$ & $.62^{\mathrm{c}}$ & $.37^{\mathrm{c}}$ & $.23^{\mathrm{b}}$ & $.43^{\mathrm{c}}$ & & \\
\hline 7 & Positive youth development & .10 & $.24^{\mathrm{b}}$ & $.62^{\mathrm{c}}$ & $.35^{\mathrm{c}}$ & .10 & $.36^{\mathrm{c}}$ & \\
\hline 8 & Life satisfaction & .01 & .08 & $.32^{\mathrm{c}}$ & $.51^{\mathrm{c}}$ & .06 & $.21^{\mathrm{b}}$ & $.64^{\mathrm{c}}$ \\
\hline
\end{tabular}

\section{Discussion}

In the contemporary higher education, growing financial and human resource has been invested to promote students' leadership development (Dugan and Komives 2007). However, it is still inconclusive about whether such a great investment is worthy due to the inadequate rigorous evaluation (Posner 2009). Besides, it is unknown whether students' leadership development benefits or endangers their well-being. Therefore, we addressed these questions based on a leadership course that nurtures service leadership of college students. First, with a quasi-experimental design, our study found that students who attended this leadership course showed greater enhancement in

Table 4 Coefficients of cross-lagged models

\begin{tabular}{|c|c|c|c|c|c|c|}
\hline & \multicolumn{6}{|l|}{$\mathrm{B}(\mathrm{SE})$} \\
\hline & $\mathrm{CC}$ & $\mathrm{CA}$ & TS1 & TS2 & CLE1 & CLE2 \\
\hline Knowledge and life satisfaction & $-.04(.28)$ & $.41(.36)$ & $.66(.07)^{\mathrm{c}}$ & $.52(.07)^{\mathrm{c}}$ & $-.004(.01)$ & $1.3(.59)^{\mathrm{a}}$ \\
\hline Attitudes and life satisfaction & $.03(.01)^{\mathrm{a}}$ & $.07(.02)^{\mathrm{b}}$ & $.58(.06)^{\mathrm{c}}$ & $.52(.07)^{\mathrm{c}}$ & $-.08(.13)$ & $.05(.03)$ \\
\hline $\begin{array}{l}\text { Knowledge and positive youth } \\
\text { development }\end{array}$ & $.14(.17)$ & $.46(.23)$ & $.67(.07)^{\mathrm{c}}$ & $.64(.06)^{\mathrm{c}}$ & $.000(.00)$ & $.06(.94)$ \\
\hline $\begin{array}{l}\text { Attitudes and positive youth } \\
\text { development }\end{array}$ & $.03(.01)^{\mathrm{b}}$ & $.08(.02)^{\mathrm{c}}$ & $.55(.06)^{\mathrm{c}}$ & $.66(.07)^{\mathrm{c}}$ & $-.05(.08)$ & $.10(.05)^{\mathrm{a}}$ \\
\hline
\end{tabular}

CC, Correlated change; CA, Concurrent association; TS1, Temporal stability of leadership variable; TS2, Temporal stability of well-being variable; CLE1, Cross-lagged effect of leadership variable on well-being variable; CLE2, Cross-lagged effect of well-being variable on leadership variable

${ }^{\mathrm{a}} p<.05$

${ }^{\mathrm{b}} p<.01$

${ }^{\mathrm{c}} p<.001$ 
service leadership capacities in terms of knowledge and attitudes and well-being in terms of life satisfaction, compared with those who had never attended this course. Second, the pretest-posttest change in service leadership attitudes but not knowledge was positively related to the change in life satisfaction and positive youth development.

Results of the current study point to at least two conclusions that are theoretically important and practically enlightening. First, leadership capacities can be nurtured. Our findings are more convincing compared with evaluation studies with pre-experimental design and correlational studies (e.g., Shek and Lin 2015), as they were derived from a quasi-experimental design that can inform (though cannot fully demonstrate) the potential cause-and-effect link between leadership program and developmental outcomes.

Contemporary student leadership development theories (e.g., Kouzes and Posner 2002; Rost and Barker 2000; Shek et al. 2018) conceptualized leadership in relation to the contribution to the common good, and uphold the cultivation of capacities that enable one to transcend beyond the self in a leadership process, including moral values such as integrity, other-oriented qualities such as caring toward others, and a service mindset. The course "Service Leadership" demonstrated that the knowledge about and positive attitudes toward these leadership ideologies are educable. These leadership capacities are important, as when students understand the theories underlying service leadership and endorse the beliefs and values of the service leadership, they are more likely to reflect on and make their behaviors congruent with service leadership (see Owen 2012). The success of the course may be due to the experiential and reflective learning approach which has been regarded as critical to maximize leadership learning effectiveness (Dugan and Komives 2010; Eich 2008; Riggio et al. 2003; Wisniewski 2010). The teachers adopted multiple approaches to facilitate students' engagement and reflection. According to Roberts (2008)'s survey among university students, five class activities were regarded as having the greatest impact on learning, which included relating the materials to students' lives, watching videos about course concepts, group discussion, discussion with classmates and teachers, and leading a discussion. Most of the activities were employed in the service leadership class. For example, teachers often conducted group discussions, and sometimes, a debate to facilitate the learning. Differences and disagreement may inspire students to think and reflect (Kolb and Kolb 2009).

The successful case of the course "Service Leadership" informs leadership educators that class learning can be an effective approach to nurture leadership capacities. Compared with the leadership programs that involve outside activities such as community service, positional training, and leadership retreats, in-class learning can reach more students and is less costly. Tertiary institutions may consider incorporating leadership course into the curriculum so as to maximize the number of students benefiting from leadership programs.

The second conclusion is that leadership development is related to the growth of well-being among college students. Contemporary theories of student leadership development have integrated development in cognitive and psychosocial domains (Owen 2012). Accordingly, leadership programs are encouraged to promote the personal growth of students beyond learning specific skills. The course "Service Leadership" exemplifies this holistic approach. For example, teachers tried to enhance students' selfawareness and self-understanding in different domains such as their competencies, 
character strengths, and purpose in life. With a holistic development objective, it is likely that leadership program can foster student well-being. Our findings echo the argument of Stephens and Beatty (2015) that leadership development would transform many aspects of life beyond leadership. They used the social change model of leadership development to conceptually illustrate how capacities of social responsible leadership contribute to academic determination, engaged learning, diverse citizenship, social connectedness, and positive perspective. We further provided empirical evidence that leadership development can foster life satisfaction.

However, we did not find support for the positive impact of the course on positive youth development. On the one hand, there are multiple college experiences that may contribute to the growth of students' positive functioning. For example, taking a servicelearning course which integrates community service and reflection will contribute to social competence and moral competence (Conway et al. 2009). Therefore, a single leadership course may not outperform other college experiences. On the other hand, we used a brief scale which might not fully capture students' specific positive functioning. For example, emotional competence was measured by one item about emotional management, but emotional competence also entails recognition, discrimination, and use of emotions (Mayer et al. 1999). Future studies that use a longer measurement tool may inform more about the role of leadership program in enhancing positive functioning.

The effectiveness in promoting life satisfaction has implications for multiple stakeholders of leadership programs. It informs educational leaders that the value of leadership programs can be extended to student well-being, and thus it deserves more investment. In the design and implementation of leadership programs, educators can think more about how to maximize the positive impact on student well-being. For example, nurturing leadership through a holistic lens may be an effective way. Researchers also need to incorporate student well-being into the understanding of leadership development process, try to identify the breadth and strength of the leadership program effects on student well-being, and figure out the leadership development factors that are more relevant to student well-being.

Our study provides preliminary evidence for factors related to the growth in wellbeing. Although knowing and being are two important components of student development (see Komives et al. 2013), our study indicates that one's internal positive attitudes toward service leadership are more related to their well-being. Service leadership attitudes represent a set of humanistic and systemic leadership attitudes (see Wielkiewicz and Stelzner 2005). For example, it emphasizes everyone's potential to become a leader and the importance of possessing moral character and demonstrating caring behavior in the leadership process. Adopting such leadership attitudes reflect a more mature leadership identity (Komives et al. 2005). Also, it may positively influence how students view themselves and their lives. Thus, it may nurture students' well-being. In contrast, simply obtaining more service leadership knowledge seems not helpful to well-being. Some students may just learn the knowledge for a better grade instead of striving to reflect on the service leadership beliefs and values and turn it into their own internal attitudes.

These findings are very enlightening to leadership educators. Although leadership program usually entails knowledge, attitudes and skills, leadership educators may need to know that the transformation of attitudes is more important for students to live a good life, compared with the acquisition of knowledge. However, attitudinal change cannot be 
forced (Owen 2012). Leadership program should create better opportunities and environments which facilitate students to obtain insights with the guidance of the teachers.

Several limitations of this study should be noted. First, the current conclusion relied on one leadership course, and thus the generalizability may be limited. Second, the correlated change findings represent a correlational relationship instead of a causal relationship, and thus we could not exclude the possibility of a reverse causality, that is, well-being fosters the enhancement in service leadership attitudes. The cross-lagged effect of positive youth development on service leadership attitudes detected in this study suggests that it is possible that students with greater positive youth development levels are readier to endorse service leadership attitudes. Nevertheless, the current study at least indicates that leadership development goes hand in hand with well-being growth. We suggest future studies to measure the variables on multiple time points, which enables researchers to investigate whether the growth in service leadership attitudes would lead to greater subsequent well-being through latent growth curve modeling (see Wang and Pomerantz (2009) for an example). Finally, it is possible that the improvement detected between the pretest and posttest represents a "honeymoon effect" that would fade out with time (Rosch and Schwartz 2009). To test whether the effectiveness of leadership programs would last long, future studies are encouraged to adopt a follow-up test a few months after the completion of the program.

Despite the shortcomings, we believe the current study offers new insights to researchers and practitioners interested in leadership programs and well-being of young people. We provided evidence to support the view that leadership capacities can be taught. By linking leadership program to student well-being, we open-up a new direction of research that explicates the relationship between leadership development and well-being of youngsters.

Acknowledgements This paper was presented at the Annual Conference of the International Society of Quality for Life Studies at Innsbruck, Austria in September 2017. This paper and the related research project on the development of the assessment tools for the Service Leadership Model are financially supported by the Victor and William Fung Foundation and the Endowed Professorship in Service Leadership and Education at The Hong Kong Polytechnic University.

\section{Compliance with Ethical Standards}

Conflict of Interest The authors declared no potential conflicts of interest with respect to the research, authorship, and/or publication of this article.

Open Access This article is distributed under the terms of the Creative Commons Attribution 4.0 International License (http://creativecommons.org/licenses/by/4.0/), which permits unrestricted use, distribution, and reproduction in any medium, provided you give appropriate credit to the original author(s) and the source, provide a link to the Creative Commons license, and indicate if changes were made.

\section{References}

Allemand, M., \& Martin, M. (2016). On correlated change in personality. European Psychologist, 21, $237-253$. Astin, H. S., \& Astin, A. W. (1996). A social change model of leadership development: Guidebook (version iii). Los Angeles: University of California.

Bass, B. M., \& Steidlmeier, P. (1999). Ethics, character, and authentic transformational leadership behavior. The Leadership Quarterly, 10(2), 181-217. 
Binard, K., \& Brungardt, C. (1997). Learning leadership: Assessing students at the Community College of Denver. Journal of Leadership Studies, 4(4), 128-140.

Black, A. M., \& Earnest, G. W. (2009). Measuring the outcomes of leadership development programs. Journal of Leadership and Organizational Studies, 16(2), 184-196.

Brungardt, C., Greenleaf, J., Brungardt, C., \& Arensdorf, J. (2006). Majoring in leadership: A review of undergraduate leadership degree programs. Journal of Leadership Education, 5(1), 4-25.

Chung, P. (2011). HKI-SLAM definition of Service Leadership. Retrieved from http://hki-slam.org/index. php? $\mathrm{r}=$ article \&catid=1\&aid=11\#leadership

Chung, P., \& Bell, A. H. (2012). Service reborn: The knowledge, skills and attitudes of service companies (1st ed.). New York: Lexingford Publishing.

Chung, P., \& Bell, A. H. (2015). 25 principles of Service Leadership (1st ed.). New York: Lexingford Publishing.

Colfax, R. S., Rivera, J. J., \& Perez, K. T. (2010). Applying emotional intelligence (EQ-I) in the workplace: Vital to global business success. Journal of International Business Research, 9(1), 89-98.

Conway, J. M., Amel, E. L., \& Gerwien, D. P. (2009). Teaching and learning in the social context: A metaanalysis of service learning's effects on academic, personal, social, and citizenship outcomes. Teaching of Psychology, 36(4), 233-245.

Cress, C. M., Astin, H. S., Zimmerman-Oster, K., \& Burkhardt, J. C. (2001). Developmental outcomes of college students' involvement in leadership activities. Journal of College Student Development, 42(1), 15-27.

Diener, E., Emmons, R. A., Larsen, R. J., \& Griffin, S. (1985). The Satisfaction With Life Scale. Journal of Personality Assessment, 49(1), 71-75.

Dugan, J. P., \& Komives, S. R. (2007). Developing leadership capacity in college students: Findings from a national study. A report from the multi-institutional study for leadership. College Park: National Clearinghouse for Leadership Programs.

Dugan, J. P., \& Komives, S. R. (2010). Influences on college students' capacities for socially responsible leadership. Journal of College Student Development, 51(5), 525-549.

Dugan, J. P., Bohle, C. W., Gebhardt, M., Hofert, M., Wilk, E., \& Cooney, M. A. (2011). Influences of leadership program participation on students' capacities for socially responsible leadership. Journal of Student Affairs Research and Practice, 48(1), 65-84.

Eich, D. (2008). A grounded theory of high-quality leadership programs: Perspectives from student leadership development programs in higher education. Journal of Leadership and Organizational Studies, 15(2), $176-187$.

Ewing, J. C., Bruce, J. A., \& Ricketts, K. G. (2009). Effective leadership development for undergraduates: How important is active participation in collegiate organizations? Journal of Leadership Education, 7(3), 118-131.

Haber, P. (2006). Structure, design, and models of student leadership programs. In S. R. Komives, J. P. Dugan, J. E. Owen, C. Slack, \& W. Wagner (Eds.), Handbook for student leadership programs (pp. 29-51). College Park: National Clearinghouse for Leadership Programs.

Klimstra, T. A., Bleidorn, W., Asendorpf, J. B., van Aken, M. A. G., \& Denissen, J. J. A. (2013). Correlated change of Big Five personality traits across the lifespan: A search for determinants. Journal of Research in Personality, 47(6), 768-777.

Kolb, A. Y., \& Kolb, D. A. (2009). Experiential Learning Theory: A dynamic, holistic approach to management learning, education and development. In S. J. Armstrong \& C. V. Fukami (Eds.), The SAGE handbook of management learning, education and development (pp. 42-68). London: SAGE.

Komives, S. R., Owen, J. E., Longerbeam, S. D., Mainella, F. C., \& Osteen, L. (2005). Developing a leadership identity: A grounded theory. Journal of College Student Development, 46(6), 593-611.

Komives, S. R., Lucas, N., \& McMahon, T. R. (2013). Exploring leadership: For college students who want to make a difference (3rd ed.). San Francisco: Jossey-Bass.

Kouzes, J. M., \& Posner, B. Z. (2002). The leadership challenge (3rd ed.). San Francisco: Jossey-Bass.

Lusch, R. F., Vargo, S. L., \& O’Brien, M. (2007). Competing through service: Insights from service-dominant logic. Journal of Retailing, 83(1), 5-18.

Mayer, J. D., Caruso, D. R., \& Salovey, P. (1999). Emotional intelligence meets traditional standards for an intelligence. Intelligence, 27(4), 267-298.

Owen, J. E. (2012). Using student development theories as a conceptual framework in leadership education. New Directions for Student Services, 2012(140), 17-35.

Posner, B. Z. (2009). A longitudinal study examining changes in students' leadership behavior. Journal of College Student Development, 50(5), 551-563.

Riggio, R. E., Ciulla, J. B., \& Sorenson, G. J. (2003). Leadership education at the undergraduate level: A liberal arts approach to leadership development. In S. E. Murphy \& R. E. Riggio (Eds.), The future of leadership development (pp. 223-236). Mahwah: Lawrence Erlbaum Associates.

Roberts, C. (2008). Developing future leaders: The role of reflection in the classroom. Journal of Leadership Education, 7(1), 116-130. 
Rosch, D. M., \& Caza, A. (2012). The durable effects of short-term programs on student leadership development. Journal of Leadership Education, 11(1), 28-48.

Rosch, D. M., \& Schwartz, L. M. (2009). Potential issues and pitfalls in outcomes assessment in leadership education. Journal of Leadership Education, 8(1), 177-194.

Rost, J. C. (1991). Leadership for the twenty-first century. New York: Praeger.

Rost, J. C., \& Barker, R. A. (2000). Leadership education in colleges: Toward a 21st century paradigm. Journal of Leadership and Organizational Studies, 7(1), 3-12.

Royse, D. D., Thyer, B. A., \& Padgett, D. K. (2010). Program evaluation: An introduction (5th ed.). Belmont: Wadsworth.

Ryan, R. M., \& Deci, E. L. (2001). On happiness and human potentials: A review of research on hedonic and eudaimonic well-being. Annual Review of Psychology, 52(1), 141-166.

Sessa, V. I., Matos, C., \& Hopkins, C. (2009). Evaluating a college leadership course: What do students learn in a leadership course with a service-learning component and how deeply do they learn it. Journal of Leadership Education, 7(3), 167-200.

Shek, D. T. L. (2004). Chinese cultural beliefs about adversity: Its relationship to psychological well-being, school adjustment and problem behavior in Hong Kong adolescents with and without economic disadvantage. Childhood, 11(1), 63-80.

Shek, D. T. L., \& Chung, P. (Eds.). (2015). Promoting Service Leadership qualities in university students: The case of Hong Kong. Singapore: Springer.

Shek, D. T. L., \& Lin, L. (2015). Evaluating service leadership programs with multiple strategies. In D. T. L. Shek \& P. Chung (Eds.), Promoting Service Leadership qualities in university students: The case of Hong Kong (pp. 197-211). Singapore: Springer.

Shek, D. T. L., \& Lin, L. (2017). Validation of the Service Leadership Knowledge Scale: Criterion-related validity. In D. T. L. Shek, P. Chung, L. Lin, \& J. Merrick (Eds.), Service Leadership education for university students (pp. 189-204). New York: Nova Science.

Shek, D. T. L., \& Ng, E. C. W. (2017). Leadership training for university students in Hong Kong: A critical review. International Journal of Child and Adolescent Health, 10(1), 25-40.

Shek, D. T. L., Yu, L., Ma, C. M. S., Sun, R. C. F., \& Liu, T. T. (2013). Development of a credit-bearing service leadership subject for university students in Hong Kong. International Journal of Adolescent Medicine and Health, 25(4), 353-361.

Shek, D. T. L., Yu, L., \& Ma, C. M. S. (2014). The students were happy, but did they change positively? International Journal on Disability and Human Development, 13(4), 505-511.

Shek, D. T. L., Lin, L., \& Leung, H. (2017a). The evaluation of service leadership education for university students in Hong Kong. In D. T. L. Shek, P. Chung, L. Lin, \& J. Merrick (Eds.), Service leadership education for university students (pp. 151-162). New York, NY: Nova Science.

Shek, D. T. L., Lin, L., Leung, H., Yu, L., Ma, C. M. S., \& Li, X. (2017b). Content validation of the Service Leadership Attitudes Scale. In D. T. L. Shek, P. Chung, L. Lin, \& J. Merrick (Eds.), Service leadership education for university students (pp. 205-225). New York: Nova Science.

Shek, D. T. L., Lin, L., Leung, H., Yu, L., Ma, C. M. S., \& Li, X. (2017c). Development and validation of the Service Leadership Knowledge Scale in a Chinese context. In D. T. L. Shek, P. Chung, L. Lin, \& J. Merrick (Eds.), Service leadership education for university students (pp. 163-188). New York: Nova Science.

Shek, D. T. L., Yu, L., Wu, F. K. Y., Zhu, X., \& Chan, K. H. W. (2017d). A 4-year longitudinal study of wellbeing of Chinese university students in Hong Kong. Applied Research in Quality of Life, 12(4), 867-884.

Shek, D. T. L., Yuen-Tsang, A. W. K., \& Ng, E. C. W. (2017e). Global Youth Leadership Institute: A platform to nurture leadership in university students. International Journal of Child and Adolescent Health, 10(1), 17-23.

Shek, D. T. L., Chung, P., Lin, L., Leung, H., \& Ng, E. C. W. (2018). Service Leadership under the service economy. In J. L. Chin, J. E. Trimble, \& J. E. Garcia (Eds.), Global and culturally diverse leaders and leadership: New dimensions and challenges for business, education and society (pp. 143-161). UK: Emerald Publication.

Stephens, C. M., \& Beatty, C. C. (2015). Leading and thriving: How leadership education can improve firstyear student success. Journal of Leadership Education, 14(3), 119-131.

Wang, Q., \& Pomerantz, E. M. (2009). The motivational landscape of early adolescence in the United States and China: A longitudinal investigation. Child Development, 80(4), 1272-1287.

Wielkiewicz, R. M., \& Stelzner, S. P. (2005). An ecological perspective on leadership theory, research, and practice. Review of General Psychology, 9(4), 326-341.

Wisniewski, M. A. (2010). Leadership and the millennials: Transforming today's technological teens into tomorrow's leaders. Journal of Leadership Education, 9(1), 53-67. 